\title{
Brain-derived neurotrophic factor in autoimmune inflammatory diseases (Review)
}

\author{
NINGNING WANG ${ }^{1}$ and BAILING TIAN ${ }^{2}$ \\ Departments of ${ }^{1}$ Gastroenterology and ${ }^{2}$ Rheumatology and Immunology, The First Affiliated Hospital, \\ China Medical University, Shenyang, Liaoning 110001, P.R. China
}

Received March 16, 2021; Accepted August 10, 2021

DOI: $10.3892 /$ etm.2021.10727

\begin{abstract}
Numerous recent studies reported that brain-derived neurotrophic factor (BDNF) also exists in the peripheral blood to regulate the proliferation, differentiation and survival of lymphocytes. Besides the role of BDNF in neuron repair, circulatory BDNF also enhances the proliferation and reduces apoptosis of lymphocytes. Peripheral lymphocytes express both BDNF and its receptors. Increasing evidence has indicated that altered BDNF serum levels significantly affect patients with autoimmune inflammatory diseases and may also be linked to the pathogenesis of diseases. For instance, systemic lupus erythematosus, an autoimmune inflammatory disease involving multiple organs, is frequently linked to altered B lymphocyte function, imbalance of T-cell subpopulations and loss of immune tolerance, which dysregulates the immune regulatory network with excessive secretion of inflammatory cytokines. The present review summarized studies that suggest a potential link between circulatory BDNF and autoimmune inflammatory diseases.
\end{abstract}

\section{Contents}

1. Introduction

2. BDNF and its receptors

3. Peripheral blood BDNF

4. BDNF in autoimmune inflammatory diseases

5. Conclusions

Correspondence to: Dr Bailing Tian, Department of Rheumatology and Immunology, The First Affiliated Hospital, China Medical University, 155 Nanjing Street, Shenyang, Liaoning 110001, P.R. China

E-mail: tianbailing2010@163.com

Key words: brain-derived neurotrophic factor, autoimmune disease, inflammatory disease, systemic lupus erythematosus, tyrosine kinase B, lymphocyte

\section{Introduction}

In recent years, neurotrophins (NTs), particularly brain-derived neurotrophic factor (BDNF), have achieved varying degrees of success in various diseases, such as spinal cord injuries, neurodegenerative diseases and tumors (1-4). NTs are also effective against immune system diseases and are considered a novel therapeutic strategy to manage allergies or inflammation.

BDNF, a prominent member of the NT family, has been extensively studied for autoimmune inflammatory diseases. Previous studies have indicated that circulating BDNF was mainly produced from lymphocytes, macrophages, vascular endothelial cells and other immune cells $(5,6)$. BDNF promotes the survival and proliferation of lymphocytes by binding to cell membrane receptors in an autocrine or paracrine manner $(7,8)$. Of note, the production of BDNF varies among different $\mathrm{T}$ lymphocyte subpopulations (5). BDNF has been linked to systemic lupus erythematosus (SLE) (9), experimental autoimmune encephalomyelitis (EAE) (10), multiple sclerosis (MS) (11) and other autoimmune inflammatory diseases. SLE involves dysregulation of $\mathrm{T}$ and $\mathrm{B}$ lymphocyte networks (12). A previous study by our group reported on decreased circulatory levels of BDNF in SLE, which correlated with the number of $\mathrm{CD} 4^{+} \mathrm{T}$ and $\mathrm{CD}^{+} \mathrm{T}$ lymphocytes (9). So far, the pathogenesis of SLE has remained elusive. A general consensus is that the interaction of susceptible genes with certain environmental factors disrupts the regulatory networks of $\mathrm{T}$ and $\mathrm{B}$ lymphocytes, which promotes the production of characteristic pathogenic antibodies and immune complexes. In addition, $\mathrm{T}$ helper (Th) and $\mathrm{T}$ follicular helper (Tfh) cells are excessively produced, while the production of regulatory $\mathrm{T}$ cells (Treg) and inactivation of cytotoxic $\mathrm{T}$ cells are suppressed (12). The balance of inflammatory cytokines becomes disturbed and interleukin-6 (IL-6), IL-8, IL-10, IL-17, interferon- $\gamma($ IFN- $\gamma)$ and other cytokines are significantly upregulated (13). The antigen-presenting cell-mediated balance between pro-inflammatory and anti-inflammatory cytokines is vital for the differentiation of CD4 ${ }^{+}$T-cell lineages (including Th1, Th2, Th17, Tfh and Treg), which is also closely linked to the pathogenesis of SLE (14). It may be speculated that BDNF affecting the immune function of lymphocytes is a major factor in the pathogenesis of SLE. 


\section{BDNF and its receptors}

BDNF, which exists as a dimer, was first thought to only be present in the central nervous system (CNS) and synthesized by astrocytes; however, it has now also been detected in peripheral blood. BDNF dimers non-covalently bind to the membrane receptors to exert their biological effects. In general, both pre- and mature BDNF are able to bind and signal, albeit using two different families of receptors, namely the low-affinity p75 NT receptor (p75NTR) 'panneurotrophic factor' receptors (15-17) and the high-affinity tropomyosin associated kinase (TRK) receptors. BDNF binds to the high-affinity TrkB (tyrosine kinase B) receptor of the TRK family (18), while p75NTR belongs to the tumor necrosis factor (TNF) receptor superfamily (17). p75NTR is thought to be a co-receptor for TrkB (19); however, its function has remained to be fully elucidated (20). Studies suggest that p75NTR participates in pro-apoptotic processes during cell development (21), mediates the migration of Schwann cells (22) and determines the fate of certain non-neural cells (23). p75NTR, which was previously known for its weak binding, binds with high affinity to BDNF precursor (pro-BDNF), and subsequently, the resulting heterodimer binds to Sortilin, causing neuronal apoptosis and inhibition of axonal growth (24).

The other receptor, TrkB, is a transmembrane receptor with a tyrosine kinase domain encoded by the Trk proto-oncogene, which exists as either the full-length gp145TrkB or the truncated gp95TrkB (18). TrkB activation by BDNF stimulates neuronal activity, which is necessary for memory development and maintenance. The full-length gp145TrkB has a complex structure, including an extracellular binding domain for BDNF, a transmembrane region and a cytosolic tyrosine-kinase domain essential for BDNF signaling (Fig. 1). The full-length gp145TrkB, upon autophosphorylation, exposes substrate binding sites for SHC, growth factor receptor-bound protein 2, ATP and phospholipase C (PLC) $\gamma$. In general, gp145TrkB activation triggers three downstream tyrosine kinase-mediated pathways, PLC $\gamma 1 /$ PKC, MAPK-ERK and PI3/Akt, which regulate cell survival and differentiation (25). On the contrary, the truncated gp95TrkB, devoid of the tyrosine kinase domain, has a negative effect, which binds and internalizes BDNF without autophosphorylation (26). Of note, truncated gp95trkB may still mediate BDNF-induced cell proliferation but the mechanism has remained elusive. In this manner, TrkB affects both cell survival and BDNF production.

In the TrkB-p75NTR heterodimer interaction, TrkB inhibits p75NTR-induced apoptosis, while p75NTR increases the affinity of BDNF to TrkB, which promotes growth and survival of nerve cells (27).

\section{Peripheral blood BDNF}

It is becoming increasingly clear that BDNF has more functions than that of a growth factor. It is intricately intertwined with immunity, inflammation and numerous other regulatory pathways. In recent years, numerous studies have indicated that, apart from the CNS, BDNF also exists in peripheral blood, where it affects the activities of non-neuronal cells. Lymphocytes, monocytes and vascular endothelial cells are considered to be the major sources of circulatory $\operatorname{BDNF}(5,6)$.
In addition, platelets may contain BDNF (28). BDNF is expressed by both $\mathrm{CD} 4^{+}$(Th1 and $\mathrm{Th} 2$ ) and $\mathrm{CD} 8^{+} \mathrm{T}$ cells. Activated lymphocytes further increase the production of BDNF. IL- 6 and TNF- $\alpha$ may specifically enhance monocytes to secrete BDNF (29). BDNF is known to promote the maturation, proliferation and activation of $\mathrm{T}$ and $\mathrm{B}$ lymphocytes and have an anti-apoptotic effect on T lymphocytes $(7,8)$. In addition to the expression in peripheral lymphocytes $(8,30)$, TrkB is also expressed in all thymocytes (5). Of note, TrkB mRNA and protein levels have an inverse correlation with the maturation and differentiation of thymocytes; TrkB expression is upregulated in $\mathrm{CD} 4 \mathrm{CD} 8$ immature thymocytes and then progressively declines in $\mathrm{CD}^{+}$and $\mathrm{CD} 4^{+}$single-positive and $\mathrm{CD} 4^{+} \mathrm{CD} 8^{+}$mature thymocytes. The BDNF-TrkB interaction stimulates TrkB autophosphorylation, which in turn upregulates the c-fos gene in CD4 CD8 cells to improve thymocyte survival (5). Functionally deficient TrkB mice were revealed to have an increased number of pyknotic nuclei in the thymus on the 15th postnatal day, suggesting an increase in apoptotic lymphocytes, particularly in the cortical area. Likewise, Schuhmann et al (31) demonstrated that BDNF-deficient mice had significantly lower B lymphocytes in the blood, spleen and bone marrow. This development was specific to the pre-BII stage of bone marrow B cells. In addition, the total number of thymus cells decreased. Another study indicated that exogenous addition of BDNF to a serum-free mature B-cell culture reduced cell apoptosis by $15 \%$ (30). In line with this, Garcia-Suarez et al (32) reported massive lymphocyte apoptosis in the thymus of TrkB-deficient mice, while an improvement in the survival rate of thymic precursor cells was observed after treatment with BDNF (33). Furthermore, it was reported that cytokines secreted by $\mathrm{Th} 2$ are able to promote BDNF synthesis, which in turn downregulates the secretion of interferon and IL-22 by Th1 without affecting the secretion of IL-4, IL-10 from Th2. Likewise, IL- 6 and TNF- $\alpha$ are able to enhance BDNF secretion from peripheral blood monocytes (29). Overall, peripheral blood BDNF has a complex regulatory network involving lymphocytes and anti- and pro-inflammatory cytokines and performs a broad spectrum of activities in non-neural tissues, apart from its regulatory role in inflammation and autoimmune demyelination in the CNS (33-38). Based on these results, it is indicated that BDNF is a key factor in autoimmune and inflammatory diseases.

\section{BDNF in autoimmune inflammatory diseases}

Emerging evidence suggests that BDNF, as an immune function regulator, is linked to numerous autoimmune and inflammatory diseases, which is discussed in the following subsections (Table I).

$B D N F$ in EAE and MS. EAE is histologically and clinically similar to MS, which was established in an animal model to study autoimmune demyelination $(11,39)$. Myelin-reactive $\mathrm{T}$ cells of the CNS produce and release BDNF to promote post-traumatic tissue repair (39). In both EAE and MS, T cells near demyelinating lesions significantly increase the expression of BDNF to inhibit the progression of neuron injury (39). By contrast, BDNF binding to TrkB-expressing $\mathrm{T}$ cells leads to evasion of T-lymphocyte apoptosis, which is a key event 


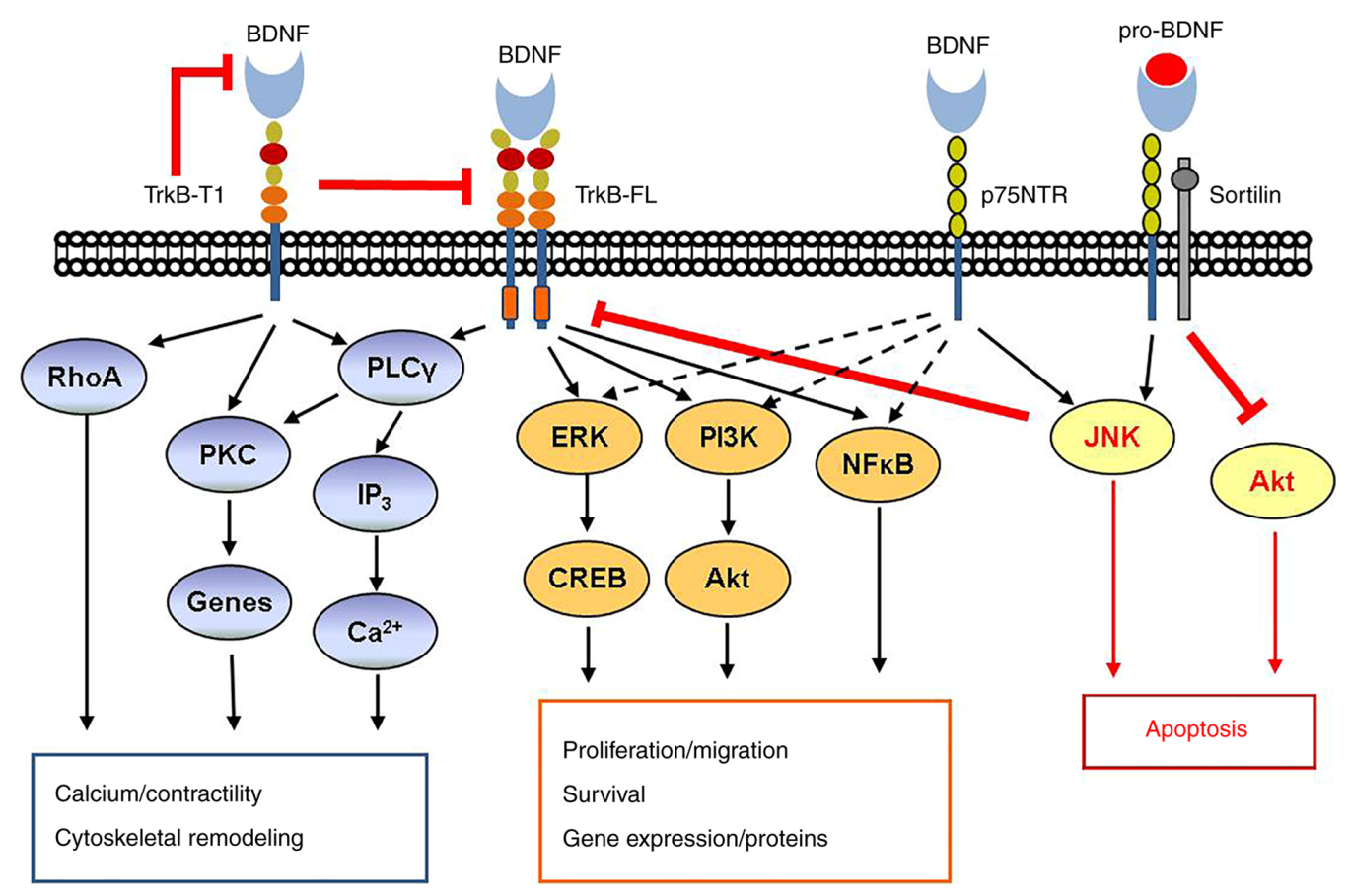

Figure 1. BDNF signaling pathway. BDNF signaling via TrkB and p75NTR is complex. Activation of TrkB-FL by mature BDNF classically leads to activation of PLC $\gamma$ and both the ERK pathway and the PI3K/Akt pathway promote cell proliferation and survival. In addition, TrkB may act through the NFKB pathway. In contrast to TrkB-FL, the truncated TrkB-T1 may be both inhibitory and activating via RhoA and PKC, resulting in cytoskeletal remodeling, gene modulation and other effects. The low-affinity p75NTR, when activated by mature BDNF, typically activates the pathway including TrkB-FL, but importantly, it may be inhibited via either the JNK or Akt pathways. This is particularly the case when p75NTR is activated by pro-BDNF and forms a ternary complex with the adaptor protein sortilin. BDNF, brain-derived neurotrophic factor; TrkB-FL, tyrosine kinase B full-length; PLC, phospholipase C; PKC, protein kinase C; NTR, neurotrophin receptor; CREB, C-response binding element; RhoA, ras homolog gene family, member A.

of the chronic inflammatory process in which $\mathrm{T}$ cells are involved (39). Therefore, it is worthwhile determining whether T cell-derived BDNF promotes neuronal recovery or promotes the persistence of inflammation. A study reported that mice deficient in immune cells producing BDNF displayed attenuated immune response in the acute phase of EAE, which reduced further brain parenchymal injury but enhanced axonal loss in the chronic phase progressing into disability. Of note, transfection of T cells expressing BDNF strongly reduced brain damage in EAE and protected axons (40). Elevated serum BDNF levels have also been associated with nerve repair in patients with MS (11).

BDNF in inflammatory bowel diseases and pulmonary sarcoidosis. Steinkamp et al (41) reported increased expression of BDNF and TrkB in local intestinal lesions of Crohn's disease (CD). In CD, enteric glial cells (EGCs) maintain the integrity of the bowel, while a loss of EGCs causes severe inflammation of the intestine. BDNF attenuates apoptosis of glial cells, while BDNF-neutralizing antibodies markedly increase apoptosis. Therefore, it is speculated that BDNF protects from CD by decreasing the apoptosis of EGCs. Glial-derived neurotrophic factor promoting an anti-apoptotic loop in EGCs has a similar role to that in CD $(42,43)$. Johansson et al (44) reported that NTs may also be involved in ulcerative colitis, in which massive inflammation exhibited a strong correlation with decreased NT immunoreaction. In addition, the production of NT increased in lamina propria cells. In pulmonary sarcoidosis, nerve growth factor (NGF) expression in alveolar macrophages increased with the increase in expression of NGF and BDNF in $\mathrm{CD} 4^{+}$and $\mathrm{CD} 8^{+} \mathrm{T}$ cells. An increased expression of TrkA, TrkB and TrkC receptors was also noticed. Furthermore, there was a significant correlation between the expression of NTs in CD4 or CD8 cell populations and the CD4:CD8 ratio, lymphocyte number, and radiological staging $(45,46)$. Overall, these results suggested that increased levels of NTs in bronchoalveolar lavage fluid modulate the functions of immune cells in pulmonary sarcoidosis.

BDNF in connective tissue diseases. The role of BDNF in autoimmune diseases has been studied extensively. In systemic sclerosis (SSc), which is a microvascular disease, serum BDNF levels are decreased (47), particularly in diffuse SSc and in SSc with pulmonary arterial hypertension or anti-Scl-70 antibodies. Of note, BDNF and TrkB are also synthesized by capillary and arterial endothelial cells (48). Therefore, decreased BDNF levels in SSc may also be linked to microvascular disease and oxidative stress. Fauchais et al (49) and Li et al (50) studied serum BDNF levels in patients with primary Sjogren's syndrome (pSS). They detected high serum BDNF levels in pSS, which were correlated with the extent of systemic involvement. NGF and BDNF levels also correlated with the activation of $\mathrm{B}$ and $\mathrm{T}$ cells; specifically, the BDNF concentration was correlated with $\mathrm{CD}^{+} \mathrm{T}$-cell activation assessed as human leukocyte antigen DR expression. Li et al (50) reported that, compared with patients with simple pSS or healthy controls, patients with pSS with interstitial lung disease (ILD) had lower serum BDNF levels, which may be used as a potential biomarker of ILD secondary to pSS. In rheumatoid arthritis (RA), plasma BDNF levels were 
Table I. BDNF and autoimmune inflammatory diseases.

\begin{tabular}{|c|c|c|c|}
\hline Autoimmune disease & Serum or tissue & BDNF level in disease & (Refs.) \\
\hline $\begin{array}{l}\text { Experimental autoimmune } \\
\text { encephalomyelitis; } \\
\text { multiple sclerosis }\end{array}$ & $\mathrm{T}$ cells in the CNS & $\begin{array}{l}\text { Strong expression of BDNF in T cells near } \\
\text { demyelinating lesions, suggesting that BDNF } \\
\text { inhibited further parenchymal injury and } \\
\text { participated in neuroinflammatory responses } \\
\text { during repair. However, BDNF partially resists } \\
\text { activation of T lymphocyte apoptosis, which may } \\
\text { be the nature of chronic inflammatory processes. }\end{array}$ & $(11,39,40)$ \\
\hline $\mathrm{CD}$ & Local intestinal lesions & $\begin{array}{l}\text { Local intestinal lesions in patients with CD with } \\
\text { strong expression of BDNF and TrkB, and BDNF } \\
\text { attenuated the apoptosis of glial cells to a small } \\
\text { extent, protecting the integrity of the bowel. }\end{array}$ & $(41-43)$ \\
\hline Ulcerative colitis & Local intestinal lesions & $\begin{array}{l}\text { Massive inflammation was correlated with } \\
\text { decreased neurotrophin immunoreaction in nerve } \\
\text { structures and there was a tendency toward } \\
\text { increased neurotrophin production in lamina } \\
\text { propria cells. }\end{array}$ & (44) \\
\hline Pulmonary sarcoidosis & $\begin{array}{l}\mathrm{T} \text { cells in bronchoalveolar } \\
\text { lavatory fluid }\end{array}$ & $\begin{array}{l}\mathrm{NGF} \text { and } \mathrm{BDNF} \text { in } \mathrm{CD}^{+} \text {and } \mathrm{CD} 8^{+} \mathrm{T} \text { lymphocytes } \\
\text { in the lung were increased in pulmonary sarcoidosis. } \\
\text { Expression of TrkB receptors was increased. There } \\
\text { was a significant correlation between lymphocytosis, } \\
\text { radiological stage and CD4 or CD8 NT expression. }\end{array}$ & $(45,46)$ \\
\hline $\mathrm{SSc}$ & Serum & $\begin{array}{l}\text { Low serum BDNF level, particularly in diffuse } \\
\text { SSc and in patients with pulmonary arterial } \\
\text { hypertension or anti-Scl- } 70 \text { antibodies. }\end{array}$ & (47) \\
\hline $\mathrm{pSS}$ & Serum & $\begin{array}{l}\text { Decreased BDNF level in pSS with ILD. BDNF } \\
\text { was correlated with the activation of B and T cells. }\end{array}$ & $(49,50)$ \\
\hline RA & $\begin{array}{l}\text { Plasma and synovial } \\
\text { tissue/SF }\end{array}$ & $\begin{array}{l}\text { Higher plasma BDNF level in RA, BDNF level } \\
\text { in synovial tissue/SF was not correlated with } \\
\text { the number of inflammatory cells or TNF- } \alpha \text { or } \\
\text { ESR, but plasma BDNF level was decreased } \\
14 \text { weeks after the initiation of anti-TNF therapy. }\end{array}$ & $(51)$ \\
\hline SpA & $\begin{array}{l}\text { Plasma and synovial } \\
\text { tissue/SF }\end{array}$ & $\begin{array}{l}\text { mRNA transcripts of all NTs and receptors were } \\
\text { highly expressed in the inflamed synovium, } \\
\text { correlating with vascularity and lymphoid } \\
\text { aggregates. BDNF level was higher in the SF of } \\
\text { patients with SpA than in OA. }\end{array}$ & $(52,53)$ \\
\hline SLE & Serum and plasma & $\begin{array}{l}\text { Serum/plasma BDNF levels in SLE are correlated } \\
\text { with SLEDAI scores and clinical parameters: C3, } \\
\text { C4 and T-cell subsets. Serum BDNF levels may } \\
\text { be decreased in active SLE. }\end{array}$ & $(9,55,59,60)$ \\
\hline
\end{tabular}

BDNF, brain-derived neurotrophic factor; CNS, central nervous system; TrkB, tyrosine kinase B; NGF, nerve growth factor; NTs, neurotrophins; TNF, tumor necrosis factor; ILD, interstitial lung disease; ESR, erythroid sedimentation rate; OA, osteoarthritis; SLE, systemic lupus erythematosus; SF, synovial fluid; SLEDAI, SLE disease activity index; SpA, spondyloarthritis; RA, rheumatoid arthritis; pSS, primary Sjogren's syndrome; SSc, systemic sclerosis; CD, Crohn's disease; C3, complement component 3.

increased; however, the concentration did not correlate with the number of inflammatory cells, the concentration of TNF- $\alpha$, erythrocyte sedimentation rate or white blood cell counts in synovial tissue (51). Of note, plasma BDNF levels decreased after 14 weeks of anti-TNF therapy. In spondyloarthritis (SPA),
RA and osteoarthritis (OA), mRNA transcripts of all NTs and receptors were expressed in the inflamed synovium. At the protein level, BDNF was significantly higher in the synovial fluid of patients with SPA than in those with OA. Immunohistochemistry demonstrated that TrkA and NGF 
were highly expressed in the inflamed synovium of patients with SPA, correlating with vascularity and lymphoid aggregates. Additionally, the immunoreactivity of all receptors was significantly decreased after infliximab treatment $(52,53)$.

$B D N F$ in SLE. Recently, serum BDNF levels in SLE have been receiving increasing attention (54-59) and have been linked to various clinical parameters, suggesting the involvement of BDNF in the pathogenesis and progression of SLE. Fauchais et al (58) indicated that the serum levels of BDNF and the SLE disease activity index (SLEDAI) were not correlated. Although BDNF levels were reduced after treatment, they remained higher in patients with SLE than in healthy controls. They speculated that BDNF levels were independent of the Th1 and Th2 profile. Furthermore, BDNF levels were the lowest in a subgroup of lupus anticoagulant-positive patients, which may have been due to antiphospholipid antibody-induced vascular lesions and oxidative stress, as in SSc (47). Ikenouchi et al (56) also reported that serum BDNF levels did not correlate with SLEDAI. However, significantly increased BDNF levels exhibited a good correlation with psychiatric symptoms, including acute state of confusion, anxiety disorder, cognitive dysfunction, mood disorder and psychosis in neuropsychiatric syndrome of SLE (NPSLE). Ikenouchi-Sugita et al (54) and Ikenouchi et al (56) suggested that plasma BDNF levels and the catecholamine metabolites have a higher predictive value regarding the severity of psychotic symptoms in SLE, offering an alternate diagnosis to steroid-induced psychosis. Of note, Tamashiro et al (55) demonstrated that increased plasma BDNF levels did not correlate with CNS lesions, which contradicts previous studies. In addition, they proved a negative correlation between plasma BDNF levels and SLEDAI and a positive correlation with the levels of complements and the numbers of circulatory lymphocytes. Zheng et al (59) suggested that decreased serum BDNF levels aggravated depression, while increased BDNF improved depression in SLE. The serum BDNF levels exhibited an increase in the stable stage of SLE and a decrease in the active stage. A study by our group indicated that the BDNF concentration decreased after repeated thawing of blood samples, suggesting poor stability of BDNF protein (9). In this study, blood samples were collected during the same period for ELISA analysis within three months. However, in the study by Tamashiro et al (55), the blood samples of the control group were from the serum banks of clinical hospitals, which may have had lower BDNF protein levels due to degradation during long-term preservation. This notion is in agreement with the study by Zuccato et al (60), who also demonstrated a time-dependent change in serum BDNF levels due to different sample storage conditions. The study by our group indicated that BDNF levels were correlated with the SLEDAI, levels of complements and the numbers of circulatory lymphocytes (9). In addition, it was demonstrated that serum BDNF levels in SLE were decreased and were the lowest in NPSLE. Another study suggested that plasma BDNF levels were consistently lower in patients with NPSLE with irreversible organic brain damage than in healthy controls and the level increased with the improvement in the disease (57). Thus, elevated BDNF levels may also be used to track the recovery of brain damage in NPSLE.

\section{Conclusion}

In summary, an altered tissue or circulatory concentration of BDNF may be linked to autoimmune and inflammatory diseases. Studies in transgenic and knockout mice, particularly in adult surviving animals, revealed hitherto unknown roles of BDNF, which may be key to understanding immune disease pathologies. BDNF regulates both immune and neuroimmune interactions. Managing BDNF levels may be a potential therapeutic strategy, particularly in diseases with dysregulated production of BDNF.

\section{Acknowledgements}

Not applicable.

\section{Funding}

No funding was received.

\section{Availability of data and materials}

Not applicable.

\section{Authors' contributions}

BT and NW analyzed the literature and prepared the manuscript. All authors read and approved the manuscript. Data authentication is not applicable.

\section{Ethics approval and consent to participate}

Not applicable.

\section{Patient consent for publication}

Not applicable.

\section{Competing interests}

The authors declare that they have no competing interests.

\section{References}

1. Blesch A and Tuszynski MH: Spontaneous and neurotrophin-induced axonal plasticity after spinal cord injury. Prog Brain Res 137: 415-423, 2002.

2. Iarikov DE, Kim BG, Dai HN, McAtee M, Kuhn PL and Bregman BS: Delayed transplantation with exogenous neurotrophin administration enhances plasticity of corticofugal projections after spinal cord injury. J Neurotrauma 24: 690-702, 2007.

3. Benussi L, Binetti G and Ghidoni R: Loss of neuroprotective factors in neurodegenerative dementias: The end or the starting point? Front Neurosci 11: 672, 2017.

4. Palasz E, Wysocka A, Gasiorowska A, Chalimoniuk M, Niewiadomski $\mathrm{W}$ and Niewiadomska G: BDNF as a promising therapeutic agent in Parkinson's disease. Int J Mol Sci 21: 1170, 2020.

5. Ziemssen T, Kümpfel T, Schneider H, Klinkert WE, Neuhaus O and Hohlfeld R: Secretion of brain-derived neurotrophic factor by glatiramer acetate-reactive T-helper cell lines: Implications for multiple sclerosis therapy. J Neurol Sci 233: 109-112, 2005.

6. Nakahashi T, Fujimura H, Altar CA, Li J, Kambayashi J, Tandon NN and Sun B: Vascular endothelial cells synthesize and secrete brain-derived neurotrophic factor. FEBS Lett 470: 113-117, 2000. 
7. D'Onofrio M, de Grazia U, Morrone S, Cuomo L, Spinsanti P, Frati L, Gulino A and Ragona G: Expression of neurotrophin receptors in normal and malignant B lymphocytes. Eur Cytokine Netw 11: 283-291, 2000.

8. Skaper SD: The biology of neurotrophins, signalling pathways, and functional peptide mimetics of neurotrophins and their receptors. CNS Neurol Disord Drug Targets 7: 46-62, 2008.

9. Tian B, Yang C, Wang J, Hou X, Zhao S, Li Y and Yang P: Peripheral blood brain-derived neurotrophic factor level and tyrosine kinase B expression on $\mathrm{T}$ lymphocytes in systemic lupus erythematosus: Implications for systemic involvement. Cytokine 123: 154764, 2019.

10. Lühder F, Gold R, Flügel A and Linker RA: Brain-derived neurotrophic factor in neuroimmunology: Lessons learned from multiple sclerosis patients and experimental autoimmune encephalomyelitis models. Arch Immunol Ther Exp (Warsz) 61: 95-105, 2013

11. Hu ZL, Luo C, Hurtado PR, Li H, Wang S, Hu B, Xu JM, Liu Y, Feng SQ, Hurtado-Perez E, et al: Brain-derived neurotrophic factor precursor in the immune system is a novel target for treating multiple sclerosis. Theranostics 11: 715-730, 2021.

12. Kleczynska W, Jakiela B, Plutecka H, Milewski M, Sanak M and Musial J: Imbalance between Th17 and regulatory T-cells in systemic lupus erythematosus. Folia Histochem Cytobiol 49: 646-653, 2011

13. Yoshio T, Okamoto H, Kurasawa K, Dei Y, Hirohata S and Minota S: IL-6, IL-8, IP-10, MCP-1 and G-CSF are significantly increased in cerebrospinal fluid but not in sera of patients with central neuropsychiatric lupus erythematosus. Lupus 25 : 997-1003, 2016.

14. Kawai T and Akira S: Toll-like receptors and their crosstalk with other innate receptors in infection and immunity. Immunity 34 : 637-650, 2011.

15. Chen Y, Zeng J, Cen L, Chen Y, Wang X, Yao G, Wang W, Qi W and Kong K: Multiple roles of the p75 neurotrophin receptor in the nervous system. J Intl Med Res 37: 281-288, 2009.

16. Blöchl A and Blöchl R: A cell-biological model of p75NTR signaling. J Neurochem 102: 289-305, 2007.

17. Gao C, Zhang L, Sun D, Li J, Yao X, Zhou H and Wang Y: Roles of p75NTR in maintaining brain hemostasis and the implications for p75NTR-targeted Therapies. Curr Alzheimer Res 14 554-561, 2017

18. Deinhardt K and Chao MV: Trk receptors. Handb Exp Pharmacol 220: 103-119, 2014.

19. Meier S, Alfonsi F, Kurniawan ND, Milne MR, Kasherman MA Delogu A, Piper M and Coulson EJ: The p75 neurotrophin receptor is required for the survival of neuronal progenitors and normal formation of the basal forebrain, striatum, thalamus and neocortex. Development 146: dev181933, 2019.

20. Roux PP and Barker PA: Neurotrophin signaling through the p75 neurotrophin receptor. Prog Neurobiol 67: 203-233, 2002.

21. Kendall SE, Goldhawk DE, Kubu C, Barker PA and Verdi JM: Expression analysis of a novel p75(NTR) signaling protein, which regulates cell cycle progression and apoptosis. Mech Dev 117: 187-200, 2002

22. Enomoto M, Bunge MB and Tsoulfas P: A multifunctional neurotrophin with reduced affinity to p75NTR enhances trans planted Schwann cell survival and axon growth after spinal cord injury. Exp Neurol 248: 170-182, 2013, 2013.

23. Caroleo MC, Costa N, Bracci-Laudiero L and Aloe L: Human monocyte/macrophages activate by exposure to LPS overexpress NGF and NGF receptors. J Neuroimmunol 113: 193-201, 2001.

24. Yang CR, Zhang XY, Liu Y, Du JY, Liang R, Yu M, Zhang FQ, $\mathrm{Mu}$ XF, Li F, Zhou L, et al: Antidepressant drugs correct the imbalance between proBDNF/p75NTR/Sortilin and mature $\mathrm{BDNF} / \mathrm{TrkB}$ in the brain of mice with chronic stress. Neurotox Res 37: 171-182, 2020.

25. Ohira K and Hayashi M: A new aspect of the TrkB signaling pathway in neural plasticity. Curr Neuropharmacol 7: 276-285, 2009.

26. Cao T, Matyas JJ, Renn CL, Faden AI, Dorsey SG and Wu J: Function and mechanisms of truncated BDNF receptor TrkB.T1 in neuropathic pain. Cells 9: 1194, 2020.

27. Matusica D, Skeldal S, Sykes AM, Palstra N, Sharma A and Coulson EJ: An intracellular domain fragment of the p75 neurotrophin receptor (p75(NTR)) enhances tropomyosin receptor kinase A (TrkA) receptor function. J Biol Chem 288: 11144-11154, 2013.

28. Burnouf T, Kuo YP, Blum D, Burnouf S and Su CY: Human platelet concentrates: A source of solvent/detergent-treated highly enriched brain-derived neurotrophic factor. Transfusion 52: 1721-1728, 2012
29. Schulte-Herbrüggen O, Nassenstein C, Lommatzsch $M$, Quarcoo D, Renz H and Braun A: Tumor necrosis factor-alpha and interleukin-6 regulate secretion of brain-derived neurotrophic factor in human monocytes. J Neuroimmunol 160 204-209, 2005

30. De Santi L, Cantalupo L, Tassi M, Raspadori D, Cioni C and Annunziata P: Higher expression of BDNF receptor gp145trkB is associated with lower apoptosis intensity in T cell lines in multiple sclerosis. J Neurol Sci 277: 65-70, 2009.

31. Schuhmann B, Dietrich A, Sel S, Hahn C, Klingenspor M, Lommatzsch M, Gudermann T, Braun A, Renz H and Nockher WA: A role for brain-derived neurotrophic factor in B cell development. J Neuroimmunol 163: 15-23, 2005.

32. Garcia-Suarez O, Blanco-Gelaz MA, Lopez ML, Germana A, Cabo R, Díaz-Esnal B, Silos-Santiago I, Ciriaco E and Vega JA: Massive lymphocyte apoptosis in the thymus of functionally deficient TrkB mice. J Neuroimmunol 129: 25-34, 2002.

33. Maroder M, Bellavia D, Vacca A, Felli MP and Screpanti I: The thymus at the crossroad of neuroimmune interactions. Ann N Y Acad Sci 917: 741-747, 2000.

34. Linker R, Gold R and Luhder F: Function of neurotrophic factors beyond the nervous system: Inflammation and autoimmune demyelination. Crit Rev Immunol 29: 43-68, 2009.

35. Vega JA, García-Suárez O, Hannestad J, Pérez-Pérez M and Germanà $\mathrm{A}$ : Neurotrophins and the immune system. J Anat 203 $1-19,2003$.

36. Nockher WA and Renz H: Neurotrophins in inflammatory lung diseases: Modulators of cell differentiation and neuroimmune interactions. Cytokine Growth Factor Rev 14: 559-578, 2003.

37. Stadelmann C, Kerschensteiner M, Misgeld T, Brück W, Hohlfeld R and Lassmann H: BDNF and gp145trkB in multiple sclerosis brain lesions: Neuroprotective interactions between immune and neuronal cells? Brain 125: 75-85, 2002

38. Tabakman R, Lecht S, Sephanova S, Arien-Zakay H and Lazarovici P: Interactions between the cells of the immune and nervous system: Neurotrophins as neuroprotection mediators in CNS injury. Prog Brain Res 146: 387-401, 2004.

39. Frota ER, Rodrigues DH, Donadi EA, Brum DG, Maciel DR and Teixeira AL: Increased plasma levels of brain derived neurotrophic factor (BDNF) after multiple sclerosis relapse. Neurosci Lett 460: 130-132, 2009.

40. Linker RA, Lee DH, Demir S, Wiese S, Kruse N, Siglienti I, Gerhardt E, Neumann H, Sendtner M, Lühder F and Gold R: Functional role of brain-derived neurotrophic factor in neuroprotective autoimmunity: Therapeutic implications in a model of multiple sclerosis. Brain 133: 2248-2263, 2010.

41. Steinkamp M, Schulte N, Spaniol U, Pflüger C, Hartmann C, Kirsch J and von Boyen GB: Brain derived neurotrophic factor inhibits apoptosis in enteric glia during gut inflammation. Med Sci Monit 18: BR117-BR122, 2012

42. Steinkamp M, Gundel H, Schulte N, Spaniol U, Pflueger C, Zizer E and von Boyen GB: GDNF protects enteric glia from apoptosis: Evidence for an autocrine loop. BMC Gastroenterol 12: 6, 2012

43. Meir M, Flemming S, Burkard N, Wagner J, Germer CT and Schlegel N: The glial cell-line derived neurotrophic factor: A novel regulator of intestinal barrier function in health and disease. Am J Physiol Gastrointest Liver Physiol 310: G1118-G1123, 2016

44. Johansson M, Norrgård $O$ and Forsgren S: Study of expression patterns and levels of neurotrophins and neurotrophin receptors in ulcerative colitis. Inflamm Bowel Dis 13: 398-409, 2007.

45. Ricci A, Mariotta S, Saltini C, Falasca C, Giovagnoli MR, Mannino F, Graziano P, Sciacchitano S and Amenta F: Neurotrophin system activation in bronchoalveolar lavage fluid immune cells in pulmonary sarcoidosis. Sarcoidosis Vasc Diffuse Lung Dis 22: 186-194, 2005.

46. Dagnell C, Grunewald J, Kramar M, Haugom-Olsen H, Elmberger GP, Eklund A and Olgart Höglund C: Neurotrophins and neurotrophin receptors in pulmonary sarcoidosis-granulomas as a source of expression. Respir Res 11: 156, 2012.

47. Lise MC, Sparsa A, Marie I, Lalloué F, Ly K, Martel C, Bezanahary H, Gondran G, Loustaud-Ratti V, Bonnetblanc JM, et al: Serum neurotrophin profile in systemic sclerosis. PLoS One 5: e13918, 2010

48. Donovan MJ, Lin MI, Wiegn P, Ringstedt T, Kraemer R, Hahn R, Wang S, Ibañez CF, Rafii S and Hempstead BL: Brain derived neurotrophic factor is an endothelial cell survival factor required for intramyocardial vessel stabilization. Development 127: 4531-4540, 2000 
49. Fauchais AL, Boumediene A, Lalloue F, Gondran G Loustaud-Ratti V, Vidal E and Jauberteau MO: Brain-derived neurotrophic factor and nerve growth factor correlate with T-cell activation in primary Sjogren's syndrome. Scand J Rheumatol 38: 50-57, 2009.

50. Li YJ, Yang CS, Lei L, Wu KF, Yang PT and Xiao WG: Serum nerve grow factor and brain-derived neurotrophic factor profiles in Sjögren's syndrome concomitant with interstitial lung disease. Clin Rheumatol 33: 1161-1164, 2014.

51. Grimsholm O, Rantapää-Dahlqvist $S$, Dalén T and Forsgren $S$ : BDNF in RA: Downregulated in plasma following anti-TNF treatment but no correlation with inflammatory parameters. Clin Rheumatol 27: 1289-1297, 2008.

52. Rihl M, Kruithof E, Barthel C, De Keyser F, Veys EM, Zeidler H, Yu DT, Kuipers JG and Baeten D: Involvement of neurotrophins and their receptors in spondyloarthritis synovitis: Relation to inflammation and response to treatment. Ann Rheum Dis 64: 1542-1549, 2005.

53. Barthel C, Yeremenko N, Jacobs R, Schmidt RE, Bernateck M, Zeidler H, Tak PP, Baeten D and Rihl M: Nerve growth factor and receptor expression in rheumatoid arthritis and spondyloarthritis. Arthritis Res Ther 11: R82, 2009.

54. Ikenouchi-Sugita A, Yoshimura R, Okamoto T, Umene-Nakano W, Ueda N, Hori H, Katsuki A, Saito K, Tanaka Y and Nakamura J: Serum brain-derived neurotrophic factor levels as a novel biological marker for the activities of psychiatric symptoms in systemic lupus erythematosus. World J Biol Psychiatry 11: 121-128, 2010.

55. Tamashiro LF, Oliveira RD, Oliveira R, Frota ER, Donadi EA, Del-Ben CM, Teixeira AL and Louzada-Junior P: Participation of the neutrophin brain-derived neurotrophic factor in neuropsychiatric systemic lupus erythematosus. Rheumatology (Oxford) 53: $2182-2190,2014$
56. Ikenouchi A, Yoshimura R, Ikemura N, Utsunomiya K, Mitoma M and Nakamura J: Plasma levels of brain derived-neurotrophic factor and catecholamine metabolites are increased during active phase of psychotic symptoms in CNS lupus: A case report. Prog Neuropsychopharmacol Biol Psychiatry 30: 1359-1363, 2006.

57. Ikenouchi-Sugita A, Yoshimura R, Ueda N, Kodama Y, Umene-Nakano W and Nakamura J: Continuous decrease in serum brain-derived neurotrophic factor (BDNF) levels in a neuropsychiatric syndrome of systemic lupus erythematosus patient with organic brain changes. Neuropsychiatr Dis Treat 4: $1277-1281,2008$

58. Fauchais AL, Lise MC, Marget P, Lapeybie FX, Bezanahary H, Martel C, Dumonteil S, Sparsa A, Lalloué F, Ly K, et al: Serum and lymphocytic neurotrophins profiles in systemic lupus erythematosus: A case-control study. PLoS One 8: e79414, 2013.

59. Zheng Q, Xu MJ, Cheng J, Chen JM, Zheng L and Li ZG: Serum levels of brain-derived neurotrophic factor are associated with depressive symptoms in patients with systemic lupus erythematosus. Psychoneuroendocrinology 78: 246-252, 2017.

60. Zuccato C, Marullo M, Vitali B, Tarditi A, Mariotti C, Valenza M, Lahiri N, Wild EJ, Sassone J, Ciammola A, et al: Brain-derived neurotrophic factor in patients with Huntington's disease. PLoS One 6: e22966, 2011.

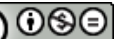

This work is licensed under a Creative Commons Attribution-NonCommercial-NoDerivatives 4.0 International (CC BY-NC-ND 4.0) License. 